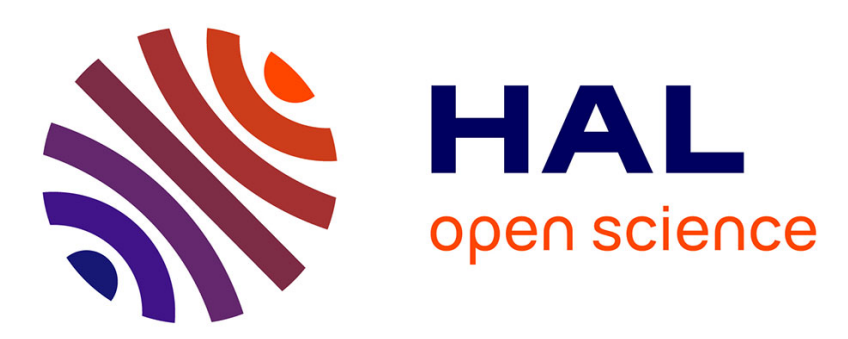

\title{
Dispatch Strategy and Model for Hybrid Photovoltaic and Trigeneration Power Systems
}

\author{
Amir Nosrat, Joshua Pearce
}

\section{To cite this version:}

Amir Nosrat, Joshua Pearce. Dispatch Strategy and Model for Hybrid Photovoltaic and Trigeneration Power Systems. Applied Energy, 2011, 68, pp.3270-3276. 10.1016/j.apenergy.2011.02.044 . hal00677846

\section{HAL Id: hal-00677846 \\ https://hal.science/hal-00677846}

Submitted on 9 Mar 2012

HAL is a multi-disciplinary open access archive for the deposit and dissemination of scientific research documents, whether they are published or not. The documents may come from teaching and research institutions in France or abroad, or from public or private research centers.
L'archive ouverte pluridisciplinaire HAL, est destinée au dépôt et à la diffusion de documents scientifiques de niveau recherche, publiés ou non, émanant des établissements d'enseignement et de recherche français ou étrangers, des laboratoires publics ou privés. 
Published as: Amir Nosrat and Joshua M. Pearce, "Dispatch Strategy and Model for Hybrid Photovoltaic and Combined Heating, Cooling, and Power Systems", Applied Energy 88 (2011) 3270-3276. http://dx.doi.org/10.1016/j.apenergy.2011.02.044

\title{
Dispatch Strategy and Model for Hybrid Photovoltaic and Trigeneration Power Systems
}

\author{
Amir Nosrat ${ }^{1}$ and Joshua M. Pearce ${ }^{1 *}$ \\ ${ }^{1}$ Department of Mechanical and Materials Engineering \\ Queen's University \\ 60 Union Street \\ Kingston, Ontario \\ K7L 3N6 Canada \\ * pearce@me.queensu.ca, ph:613-533-3369
}

\begin{abstract}
The advent of small scale combined heat and power (CHP) systems has provided the opportunity for inhouse power backup of residential-scale photovoltaic (PV) arrays. These hybrid systems enjoy a symbiotic relationship between components, but have large thermal energy wastes when operated to provide $100 \%$ of the electric load. In a novel hybrid system is proposed here of PV-trigeneration. In order to reduce waste from excess heat, an absorption chiller has been proposed to utilize the CHP-produced thermal energy for cooling of PV-CHP system. This complexity has brought forth entirely new levels of system dynamics and interaction that require numerical simulation in order to optimize system design. This paper introduces a dispatch strategy for such a system that accounts for electric, domestic hot water, space heating, and space cooling load categories. The dispatch strategy was simulated for a typical home in Vancouver and the results indicate an improvement in performance of over 50\% available when a PVCHP system also accounts for cooling. The dispatch strategy and simulation are to be used as a foundation for an optimization algorithm of such systems.
\end{abstract}

keywords: photovoltaic, $\mathrm{CHP}$, combined heating cooling and power, cogeneration, trigeneration, hybrid

\section{Introduction:}

Most work on solar photovoltaic and thermal (PV/T) systems have combined PV with some form of waste heat recovery from the panels themselves [1-6]. Although this is an efficient use of energy and can even improve PV performance it does not allow for greater PV penetration levels (percent of PV-generated electricity on the grid) because the waste heat recovery does not reduce the intermittent nature of sunlight. The recent development of small scale combined heat and power (CHP) systems has provided the opportunity for in-house power backup of residential-scale photovoltaic arrays, but it also enables the grid penetration of PV to be expanded by approximately a factor of five while reducing the carbon emissions per unit electricity [7]. First generation PV+CHP hybrids where the PV simply decreased some small fraction of the run time of the CHP, have been eclipsed by $2^{\text {nd }}$ generation systems, where the PV is expanded and is completely backed up by CHP, usually with a diesel generator. These systems have been 
Published as: Amir Nosrat and Joshua M. Pearce, "Dispatch Strategy and Model for Hybrid Photovoltaic and Combined Heating, Cooling, and Power Systems”, Applied Energy 88 (2011) 3270-3276. http://dx.doi.org/10.1016/j.apenergy.2011.02.044

investigated thoroughly, especially for residential applications [8-16]. Although PV-CHP systems effectively counter the inherent intermittency of solar energy, when designed in this way the thermal energy from the CHP unit is far from fully utilized and thus dumped lowering the efficiency of the system in a range of geographic locations [7, 17]. It has been proposed that these systems can be designed to add cooling in $3^{\text {rd }}$ generation systems to utilize a greater percentage of the heat energy available from the CHP unit, thus raising efficiencies closer to the ideal [7, 18-22]. These systems are referred to here as photovoltaic and combined cooling, heating, and power (PV-CCHP) systems or PV-trigeneration systems [23]. As opposed to their $2^{\text {nd }}$ generation counterparts, these systems expand their applicability by enabling cooling capabilities during warmer seasons by both utilizing waste heat and reducing the seasonal electrical load that is often caused by cooling equipment $[19,24]$.

The additional complexity of a PV-CCHP system over a PV-CHP system creates system dynamics that require numerical simulation in order to optimize system design. While much literature has been focused on the simulation and optimization of hybrid energy systems including PV-diesel, there has been no similar investigations into PV-CCHP systems. As such, this short communication presents a dispatch strategy, and some example case studies simulating the behavior of PV-CCHP systems, which serve as a foundation for the optimization of such systems in future work.

\section{System Overview:}

A block diagram of a PV-CCHP system is illustrated in Figure 1. In this system, only an AC load was considered. In addition, there is a thermal load for heating and cooling the required perimeter. Electricity is generated by both the PV array and the CHP unit. In order to allow for more flexibility of matching thermal loads to electric loads, conversion and storage equipment for both electric and thermal loads are also incorporated. For the electric load, an inverter is included to change any DC outputs, in particular from the battery bank and the PV array, into an AC output compatible with the user load. Similarly, a battery charger is included to store excess AC output from the CHP unit in the battery bank.

The electrical component of the system is categorized as a parallel topology [8]. In this configuration, the DC energy sources (the PV array and battery) supplies a portion of the load demand directly through the inverter that will ultimately result in higher system efficiency. The CHP unit and the inverter can operate in either parallel or stand-alone mode that allows flexibility in meeting the demand. For example, when there is a low load demand, the CHP unit or the inverter can supply the energy, while in peak load, both components can operate in parallel, which can allow for the reduction in capacity of the inverter and CHP unit. Other advantages of this design include better supply-demand correlation, maximized CHP fuel efficiency, and minimized CHP maintenance costs [15]. A series topology hybrid system would be easier to implement, but would result in lower overall system efficiencies (due to inverter and battery losses), larger inverter size, and a limited control of the CHP unit [15].

\section{\{INSERT FIGURE 1\}}


Published as: Amir Nosrat and Joshua M. Pearce, "Dispatch Strategy and Model for Hybrid Photovoltaic and Combined Heating, Cooling, and Power Systems”, Applied Energy 88 (2011) 3270-3276. http://dx.doi.org/10.1016/j.apenergy.2011.02.044

On the thermal section of the system, waste heat is collected by the heat exchanger and carried on to space heating ( $\mathrm{SH}$ ) and domestic hot water (DHW) loads when necessary. The absorption chiller, on the other hand, converts the waste heat into cool air in order to meet cooling demand.

\section{Dispatch Strategy:}

The dispatch strategy is intended to control the system such that the load requirements (electric and thermal [domestic hot water usage, space heating, and space cooling]) are met. The thermal load is further split into. In the design and optimization of such a system, it is important that the load profile is representative of the annual consumption and not subject to extreme anomalies that may lead to oversizing the system capabilities [10]. There are a number of strategies suggested by $[11,14]$ that have varied from focusing on maintaining system autonomy to ensuring $100 \%$ grid reliability and to minimizing excess power production.

In the proposed system the thermal output of a CHP unit tends to be larger than the electrical output, the dispatch strategy first prioritizes matching the electrical load and in the event that the thermal load is not met afterwards, is altered to match the thermal load. Figure 2 provides a truncated graphic representation of the dispatch strategy. In this model, the equations and logic statements are condensed representations of the power flow described below. The thermal component of the strategy is demarcated by the dashed polygon, while the electrical component pertains to outside of the polygon. Excess electric power is first placed into the batteries, and in the case the batteries are at their maximum state of charge, the electricity is dumped either onto the grid or into the ground based on whether the system is a grid-connected or stand-alone. Excess thermal power is dumped as waste heat through an exhaust. The following is an outline of the dispatch strategy:

\section{\{INSERT FIGURE 2\}}

1. The dispatch strategy begins with the output of the PV array. This component is most intermittent and the hardest to control as its performance is dependent primarily on weather characteristics that are external to the system supervisory control. There are three control pathways that concern the PV component:

a) If $I_{A C \text {,load }}(i)=\eta_{\text {inv }} \cdot \eta_{\text {chrgcntrl }} \cdot I_{P V \text {,array }}(i)$, then the control is concerned with matching the thermal requirement. (step 4)

b) If $I_{P V \text {,array }}(i)>\frac{I_{A C_{\text {,load }}(i)}}{\eta_{\text {inv } \eta_{\text {chrgcntrl }}}}$, then $\mathrm{ch}(\mathrm{i})=1$ and $x_{\text {batt,part }}(i)=\max \left(1, \frac{\frac{V_{\text {ACload }}}{V_{\text {batt,bank }}}\left\{\eta_{\text {chrgcntrl }} \cdot\left[I_{\text {AC,load }}(i)-\eta_{\text {inv }} \eta_{\text {chrgcntrl }} \cdot I_{P V, a r r a y}(i)\right]\right\}}{I_{\text {batt,bank,passible }}(i)}\right)$ so long as $S O C_{j}<S O C_{\max , j}$. If the state of charge of the battery is at its maximum, the excess electricity is dumped. The control is now concerned with matching the thermal load. (step 4) 
Published as: Amir Nosrat and Joshua M. Pearce, "Dispatch Strategy and Model for Hybrid Photovoltaic and Combined Heating, Cooling, and Power Systems", Applied Energy 88 (2011) 3270-3276. http://dx.doi.org/10.1016/j.apenergy.2011.02.044
C) If $I_{P V \text {,array }}(i)<\frac{I_{A C_{\text {,load }}(i)}}{\eta_{\text {inv } \eta_{\text {chrgentrl }}}}$, the supervisory control becomes concerned with utilizing the battery for matching the consumer electric load (step 2).

2. If $1 \mathrm{c}$ holds true, the first condition required to be met for utilizing the battery is to have a SOC higher than the $\mathrm{SOC}_{\min }$ :

a) If $S O C_{j}(i)>S O C_{\min }$, then $c h(i)=0$ and

$$
x_{\text {batt,part }}(i)=\max \left(1, \frac{\frac{V_{\text {ACload }}}{V_{\text {batt, bank }}} \mid \frac{I_{A C \text { load }}(i)}{\eta_{\text {inv }} \eta_{\text {chrgcntrl }}}-I_{P V, \text { array }}(i)}{I_{\text {batt, bank,passible }}(i)}\right) \text {. The supervisory control }
$$

is now concerned whether or not the battery and PV outputs are sufficient in matching the electrical load requirement.

i. If $I_{\text {PV,array }}(i)+\frac{V_{\text {batt, bank }}}{V_{A C \text {, load }}} I_{\text {batt,bank }}(i)=\frac{I_{A C \text {, load }}(i)}{\eta_{\text {inv }} \eta_{\text {chrgcntrl }}}$, then electrical load is met and The control is now concerned with matching the thermal load (step 4).

ii. If $I_{\text {PV,array }}(i)+\frac{V_{\text {batt, bank }}}{V_{A C_{\text {, load }}}} I_{\text {batt, bank }}(i)<\frac{I_{A C_{\text {, load }}(i)}}{\eta_{\text {inv }} \eta_{\text {chrgentrl }}}$, then $x_{\text {batt,part }}(i)$ is set to zero, and the CHP is activated. The control is now concerned whether or not the CHP and the PV outputs are sufficient in matching the electric load (step 3).

b) If $C_{j}(i) \leq S O C_{\min }$, then

$$
\begin{aligned}
& x_{C H P, \text { part }, j}(i)= \\
& \max \left(1, \frac{\left\{I_{A C, \text { load }}(i)+\eta_{\text {charger }} \cdot \eta_{\text {chrgcntrl }} \cdot \frac{V_{\text {batt, bank }}}{V_{A C, l o a d}}\left[\operatorname{SOC}_{\text {max }}-\operatorname{SOC}_{j}\right] \cdot x_{\text {batt, parallel }}-\eta_{\text {inv }} \cdot \eta_{\text {chrgcntrl }} \cdot I_{P V, \text { array }}(i)\right\} \cdot V_{A C, \text { load }}}{x_{C H P, \text { parallel }} \cdot x_{C H P, \text { nom }, j}\left(k W_{\varepsilon}\right)}\right)
\end{aligned}
$$

and $x_{C H P, p a r t, j}(i) \geq 0.5$. The supervisory control is now concerned whether or not the CHP and PV outputs are sufficient in satisfying the load.

i. If $\eta_{\text {inv }} \cdot \eta_{\text {chrgcntrl }} \cdot I_{P V \text {, array }}(i)+I_{C H P \text {,array }}(i)<I_{A C \text {,load }}(i)$, the objective function is penalized for failing to meet electric load. The control is now concerned with matching the thermal load (step 4).

ii. If $\eta_{\text {inv }} \cdot \eta_{\text {chrgcntrl }} \cdot I_{P V \text {,array }}(i)+I_{C H P \text {,array }}(i) \geq I_{A C \text {,load }}(i)$, excess

$\eta_{\text {chrgcntrl }} \cdot I_{P V \text {,array }}(i)$ is used to charge the battery and if still possible, excess $\eta_{\text {chrgcntrl }} \cdot \eta_{\text {charger }} \cdot I_{C H P \text {,array }}(i)$ is used to as well. Any excess power is dumped. The control is now concerned with matching the thermal load (step 4).

3. If 2.a.ii holds true, then

$$
\max \left(1, \frac{\left\{I_{A C, l o a d}(i)+\eta_{\text {charger }} \cdot \eta_{\text {chrgcntrl }} \cdot \frac{V_{\text {batt, bank }}}{V_{A C, l o a d}}\left[S O C_{\text {max }}-S O C_{j}\right] \cdot x_{\text {batt, parallel }}-\eta_{\text {inv }} \cdot \eta_{\text {chr gcntrl }} \cdot I_{P V, a r r a y}(i)\right\} \cdot V_{A C, l o a d}}{x_{C H P, p a r a l l e l} \cdot x_{C H P, n o m, j}\left(k W_{e}\right)}\right)
$$


Published as: Amir Nosrat and Joshua M. Pearce, "Dispatch Strategy and Model for Hybrid Photovoltaic and Combined Heating, Cooling, and Power Systems", Applied Energy 88 (2011) 3270-3276. http://dx.doi.org/10.1016/j.apenergy.2011.02.044

and $x_{C H P, \text { part }, j}(i) \geq 0.5$. The supervisory control is now concerned whether or not the CHP and PV outputs are sufficient in satisfying the load.

a) If $\eta_{\text {inv }} \cdot \eta_{\text {chrgcntrl }} \cdot I_{P V \text {, array }}(i)+I_{C H P \text {,array }}(i)=I_{A C \text {, load }}(i)$, then electrical load is met and The control is now concerned with matching the thermal load (step 4).

b) If $\eta_{\text {inv }} \cdot \eta_{\text {chrgcntrl }} \cdot I_{P V \text {,array }}(i)+I_{C H P \text {,array }}(i)>I_{A C, \text { load }}(i)$ and if $S O C_{j}(i) \leq S O C_{\text {max }, j}$ , excess $\eta_{\text {chrgcntrl }} \cdot \eta_{\text {chargor }} \cdot I_{C H P \text {,array }}(i)$ is used to charge the battery. Any excess power is dumped. The control is now concerned with matching the thermal load (step 4).

c) If $\eta_{\text {inv }} \cdot \eta_{\text {chrgcntrl }} \cdot I_{P V, \text { array }}(i)+I_{C H P, \text { array }}(i)<I_{A C, \text { load }}(i)$ and if $\operatorname{SOC}_{j}(i)>S O C_{\text {min }, j}$, then $x_{\text {batt,part }}(i)=\max \left[1, \frac{\frac{V_{\text {ACload }}}{V_{\text {batt,bank }}}\left\{\frac{I_{\text {ACload }}(i)-I_{\text {CHP,array }}(i)}{\eta_{\text {inv }} \eta_{\text {chrgcntrl }}} I_{P V, \text { array }}(i)\right\}}{I_{\text {batt, bank,passible }}(i)}\right]$. The control is now concerned whether or not all three components are sufficient in matching the electrical load.

i. If

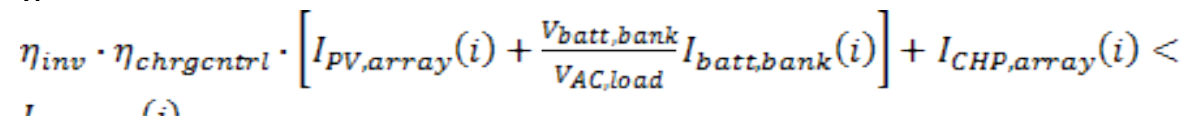

$I_{A C, \text { load }}(i)$

, the objective function is penalized for failing to meet electric load. The control is now concerned with matching the thermal load (step 4).

ii. If

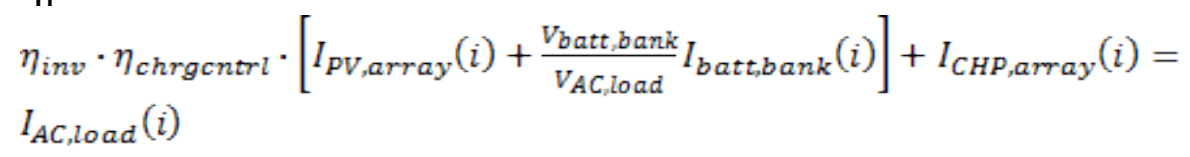

, electric load is met and control is now concerned with matching the thermal load (step 4).

4. All possible results of the dispatch strategy eventually lead up to this step, which is concerned with meeting the thermal load requirements.

a) If $Q_{\text {heat }}(i)+\frac{Q_{\operatorname{cool}(i)}}{\operatorname{COP}_{a b s}} \leq Q_{C H P \text {,array }}(i)$, any excess heat is dumped through the exhaust and the strategy is terminated for hour $i$.

b) If $Q_{\text {heat }}(i)+\frac{Q_{\text {cool }}(i)}{\operatorname{COP}_{a b s}}>Q_{C H P, a r r a y}(i)$ and $x_{C H P, p a r t, j}(i)<1$, then $x_{C H P, \text { part }, j}(i)=\max \left(1, \frac{Q_{\text {heat }}(i) \frac{\varphi_{\text {Cool }}(l)}{\operatorname{COP}_{\text {abs }}}}{x_{C H P, \text { parallel }} \cdot x_{C H P, \text { nom } j}\left(k W_{\text {th }}\right)}\right)$ and $x_{C H P, p a r t, j}(i) \geq 0.5$. The electrical output of the CHP unit has now been increased and therefore the supervisory control is now concerned with excessive electrical current.

i. If $c h(i)=1$ and $S O C_{j}(i)<S O C_{\max }$, then

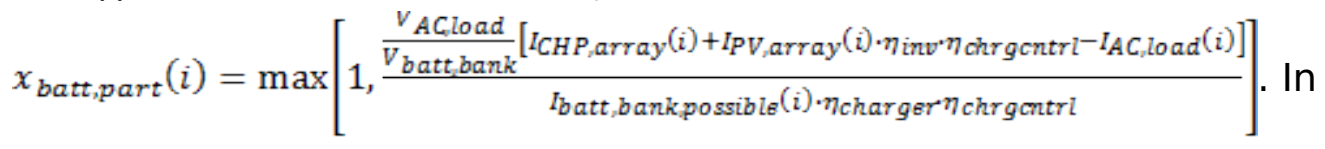


Published as: Amir Nosrat and Joshua M. Pearce, "Dispatch Strategy and Model for Hybrid Photovoltaic and Combined Heating, Cooling, and Power Systems", Applied Energy 88 (2011) 3270-3276. http://dx.doi.org/10.1016/j.apenergy.2011.02.044

the event that the maximum partial load variable for the battery is reached, any remaining $I_{C H P \text {,array }}(i)$ is dumped and the strategy is terminated for hour $i$.

ii. Otherwise if $c h(i)=0, I_{C H P \text {,array }}(i)$ is dumped and the strategy is terminated for hour $i$.

c) If $Q_{\text {hoat }}(i)+\frac{Q_{c o o l}(i)}{C_{\text {a }} a b s}>Q_{C H P, a r r a y}(i)$ and $x_{C H P, p a r t, j}(i)=1$, the objective function is penalized for failing to meet the thermal load and the strategy is terminated for hour $i$.

\section{Methodology}

The dispatch strategy shown in Figure 2 was coded and simulated using MATLAB v 7.6.0, which will also be used as a platform for future optimization. The modeled system comprised of an array of 2 strings of thirteen $70 \mathrm{~W}$ PV panels (AC W peak), a CHP engine with a capacity of $2400 \mathrm{~W}$ electrical capacity and $4000 \mathrm{~W}$ thermal capacity and a battery bank of $1000 \mathrm{amp}$-hours. The load requirements were determined from a representative profile of Vancouver created by Swan's algorithm [25]. The hourly ambient temperature and solar irradiation required to make the simulation were obtained from the PVSyst 4.37 hourly synthetic generator.

\section{Validation}

For the purposes of validating the model behavior, the algorithm was applied to a representative house in Kingston and were compared with results obtained from the Hybrid Optimization Model for Electric Renewables (HOMER), a publicly available and widely tested software developed by the National Renewable Energy Laboratory [26-28]. The least expensive optimized system for Kingston SD was selected and simulated through HOMER. The annual served electrical energy for the proposed model is equal to roughly 7,446 $\mathrm{kWh}$ compared to 7,368 for $\mathrm{kWh}$ for the HOMER simulation, or a difference of $\sim 1 \%$. This difference is attributed to constraint and penalty mechanisms in HOMER that allow the system to produce unmet load during the year. Second, the served thermal requirements were found to be mostly similar within the constraints of modeling the proposed dispatch strategy within HOMER. HOMER utilizes a thermal load-following strategy that attempts to match the boiler output to the thermal requirements at hour $i$. The proposed model and HOMER behave identically as long as the thermal requirements does not exceed the CHP system's capabilities, which in the case of Kingston SD is $3 \mathrm{kWth}$. The results from model proposed here can thus be considered to be validated based off of the much more mature HOMER model [26].

\section{Results}

To explore the simulation results, the PV-CCHP system's monthly electrical and thermal outputs were graphed for both cases including and excluding cooling loads. This data is also shown in Table 1.

Table 1. The average monthly electric loads and thermal loads with and without cooling. 
Published as: Amir Nosrat and Joshua M. Pearce, "Dispatch Strategy and Model for Hybrid Photovoltaic and Combined Heating, Cooling, and Power Systems", Applied Energy 88 (2011) 3270-3276. http://dx.doi.org/10.1016/j.apenergy.2011.02.044

\begin{tabular}{lcrr} 
& Electric Load Cooling & \multicolumn{2}{c}{ With Cooling } \\
January & 1957 & 2437 & 2437 \\
February & 1813 & 1778 & 1778 \\
March & 1873 & 1216 & 1216 \\
April & 1914 & 689 & 1741 \\
May & 1844 & 334 & 2087 \\
June & 1774 & 142 & 2428 \\
July & 1728 & 128 & 2990 \\
August & 1746 & 112 & 2530 \\
September & 1732 & 216 & 1728 \\
October & 1830 & 721 & 849 \\
November & 1835 & 1738 & 1738 \\
December & 1910 & 2696 & 2696
\end{tabular}

As clearly seen in Figure 3, the summer months account for a significant portion of the thermal load when the cooling load is taken into account. The cooling load has caused a tangible impact on the performance of the CHP unit. The CHP unit produced $1508 \mathrm{kWh}$ of thermal power and $948 \mathrm{kWh}$ of electric power more annually when accounting for space cooling, or a 59\% increase. This is primarily because of the inexorable link between thermal and electrical output of the CHP unit. This 'minimum 50\% rating' requirement is necessary to maintain high levels of efficiency for the CHP. As an alternative, the dispatch strategy can allow for the CHP to operate at lower than 50\% so long as the efficiency losses for partial load variables are taken into account. In either case, the need to consider all electric and thermal energy loads in an integrated manner is clearly demonstrated for future simulation and optimization algorithms.

As shown further in Figures 4 and 5, the thermal load and supply of the system is accounted for when looking at the hourly performance of the systems of the summer and winter periods. While the electrical load remains the same, the dynamics of the CHP and the remainder of the components are drastically changed as the proposed dispatch strategy incorporates the cooling load into its operational procedure. This provides no impact in the winter period, as predicted, but presents system shortcomings in the summertime when accounting for cooling. Accounting for these differences is integral to the modeling of PV-CCHP systems as demonstrated in the electric and thermal supply differences of Figures 4 and 5.

In this paper the ability of a PV-CCHP system to match electric, heating and cooling loads was determined for some case study locations to determine the viability of a dispatch strategy that can be used to increase PV penetration levels. Future work will focus on optimizing such systems for geographic regions and variable load profiles. 
Published as: Amir Nosrat and Joshua M. Pearce, "Dispatch Strategy and Model for Hybrid Photovoltaic and Combined Heating, Cooling, and Power Systems”, Applied Energy 88 (2011) 3270-3276. http://dx.doi.org/10.1016/j.apenergy.2011.02.044

\section{\{INSERT FIGURE 3 \} \\ \{INSERT FIGURE 4\} \\ \{INSERT FIGURE 5\}}

\section{Conclusions}

This paper overcame the limitations of available modeling techniques for hybrid systems that incapable of accounting for cooling loads by demonstrating a new simulation algorithm and dispatch strategy for the modeling of hybrid PV-CCHP systems. The results indicate a significant improvement in performance available in PV-CCHP systems over PV-CHP systems. Future work is necessary to devise a new optimization algorithm for these more complex systems.

\section{Acknowledgements}

The authors would like to acknowledge support from this project from GEOIDE/NCE and NSERC and thank L. Swan for the load models.

\section{References:}

1. Chow T. A review on photovoltaic/thermal hybrid solar technology, Applied Energy 2010; 87(2): 365-379.

2. Zondag HA. Flat-plate PV-Thermal collectors and systems: A review. Renewable and Sustainable Energy Reviews 2008;12: 891-959.

3. Charalambous PG, Maidment GG, Kalogriou SA,Yiakoumetti K. Photovoltaic thermal (PV/T) collectors: A review. Applied Thermal Engineering 2007; 27: 275-286.

4. Ji J, Lu J, Chow T, He W, Pei G. A sensitivity study of a hybrid photovoltaic/thermal waterheating system with natural circulation, Applied Energy 2007; 84(2): 222-237.

5. He W, Chow TT, Ji J, Lu J, Pei G, Chan L. Hybrid photovoltaic and thermal solar-collector designed for natural circulation of water, Applied Energy 2006; 83(3) 199-210.

6. Chow TT, Chan ALS, Fong KF, Lin Z, He W, Ji J, Annual performance of building-integrated photovoltaic/water-heating system for warm climate application, Applied Energy 2009; 86(5): 689-696.

7. Pearce J M. Expanding Photovoltaic Penetration with Residential Distributed Generation from Hybrid Solar Photovoltaic + Combined Heat and Power Systems, Energy 2009; 34:1947-1954. 
Published as: Amir Nosrat and Joshua M. Pearce, "Dispatch Strategy and Model for Hybrid Photovoltaic and Combined Heating, Cooling, and Power Systems", Applied Energy 88 (2011) 3270-3276. http://dx.doi.org/10.1016/j.apenergy.2011.02.044

8. Green H J, Manwell J. HYBRID2: A Versatile Model for the Performance of Hybrid Systems. Report by National Renewable Energy Laboratory; 1992.

9. Seeling-Hochmuth G. Optimization of Hybrid Energy Systems Sizing and Control Operations. PhD Thesis Dissertation at University of Kassel; 1999.

10. SANDIA. Stand-Alone Photovoltaic Systems: A Handbook of Recommended Design Practices, Springfield, VA: Sandia National Laboratories; 1995.

11. Nayar C, Phillips S, James W, Pryor T, and Remmer D. Novel wind/diesel/battery hybrid energy system. Solar Energy 1993; 51(1):p 65-78.

12. Manwell JF, Rogers A, Hayman G, Avelar CT, McGowan JG, Abdulwahid U, Wu K. Hybrid2-a hybrid system simulation model, Theory manual. National Renewable Energy Laboratory, Subcontract No. XL-1-11126-1-1; 2006.

13. Jennings S. Combining simulation techniques and design expertise in a renewable energy system design package, RESSAD. Solar Energy 1998; 58(4):p 265-272.

14. Ashari M, Nayar CV. An Optimum Dispatch Strategy Using Set Points for Photovoltaic (PV)Diesel Battery Hybrid Power System. Solar Energy 1999; 66(1):p 1-9.

15. Dufo-lopez R, Bernal-agustin J. Design and control strategies of PV-Diesel systems using genetic algorithms. Solar Energy, 2005; 79(1):p 33-46.

16. Ohsawa Y, Emura S, Arai K. Optimal operation of photovoltaic/diesel power generation system by neural network. Proceedings of the Second International Forum on Applications of Neural Networks to Power Systems 2002; p 99-103.

17. Borowy B, Salameh Z. Methodology for optimally sizing the combination of a battery bank and PV Array in a Wind/PV Hybrid system. IEEE Trans Energy Convers 1995;11(2): p367-75.

18. Mostofi M, Nosrat AH, Pearce JM. Institutional-Scale Operational Symbiosis of Photovoltaic and Cogeneration Energy Systems. Int. Journal of Env. Science \& Technology 2011; 8(1): 31-44.

19. Wu DW, Wang RZ. Combined cooling, heating and power: A review. Progress in Energy and Combustion Science 2006; 32:p 459-495.

20. Ziher D, Poredos A. Economics of a trigeneration system in a hospital. App Thermal Eng 2006; 26(7): p 680-687.

21. Chicco G, Mancarella P. From Cogeneration to Trigeneration: Profitable Alternatives in a Competitive Market. IEEE Transactions on Energy Conversion 2006; 21(1):p 265-272.

22. Nelson D, Nehrir M, Wang C. Unit sizing and cost analysis of stand-alone hybrid wind/PV/fuel cell power generation systems. Renewable Energy 2006; 31(10): p 1641-1656.

23. Immovilli F, Bellini A, Bianchini C, Franceschini G. Solar Trigeneration for Residential Applications, a Feasible Alternative to Traditional Micro-Cogeneration and Trigeneration Plants. Edmonton, Alberta: IEEE Industry Applications Society Annual Meeting 2008; 2008.

24. Derewonko P, Pearce JM. Optimizing Design of Household Scale Hybrid Solar Photovoltaic + Combined Heat and Power Systems for Ontario. IEEE 2009: p 1274-1279.

25. Swan LG, Residential Sector Energy and GHG Emissions Model for the Assessment of New Technologies. PhD Thesis Dissertaion. University of Dalhousie; 2010. 
Published as: Amir Nosrat and Joshua M. Pearce, "Dispatch Strategy and Model for Hybrid Photovoltaic and Combined Heating, Cooling, and Power Systems”, Applied Energy 88 (2011) 3270-3276. http://dx.doi.org/10.1016/j.apenergy.2011.02.044

26. Zhou W, Lou C, Li Z, Lu L, Yang H, Current status of research on optimum sizing of standalone hybrid solar-wind power generation systems, Applied Energy 2010; 87(2)p 380-389.

27. Seeling-Hochmuth, GC, A combined optimisation concet for the design and operation strategy of hybrid-PV energy systems. Solar Energy 1997; 61(2) p 77-87.

28. El-Amin, I, Shaahid SM, Techno-economic evaluation of off-grid hybrid photovoltaic-dieselbattery power systems for rural electrification in Saudi Arabia-A way forward for sustainable development . Renewable and Sustainable Energy Reviews 2009; 13(3): p 625-633.

\section{Figures:}


Published as: Amir Nosrat and Joshua M. Pearce, "Dispatch Strategy and Model for Hybrid Photovoltaic and Combined Heating, Cooling, and Power Systems”, Applied Energy 88 (2011) 3270-3276. http://dx.doi.org/10.1016/j.apenergy.2011.02.044

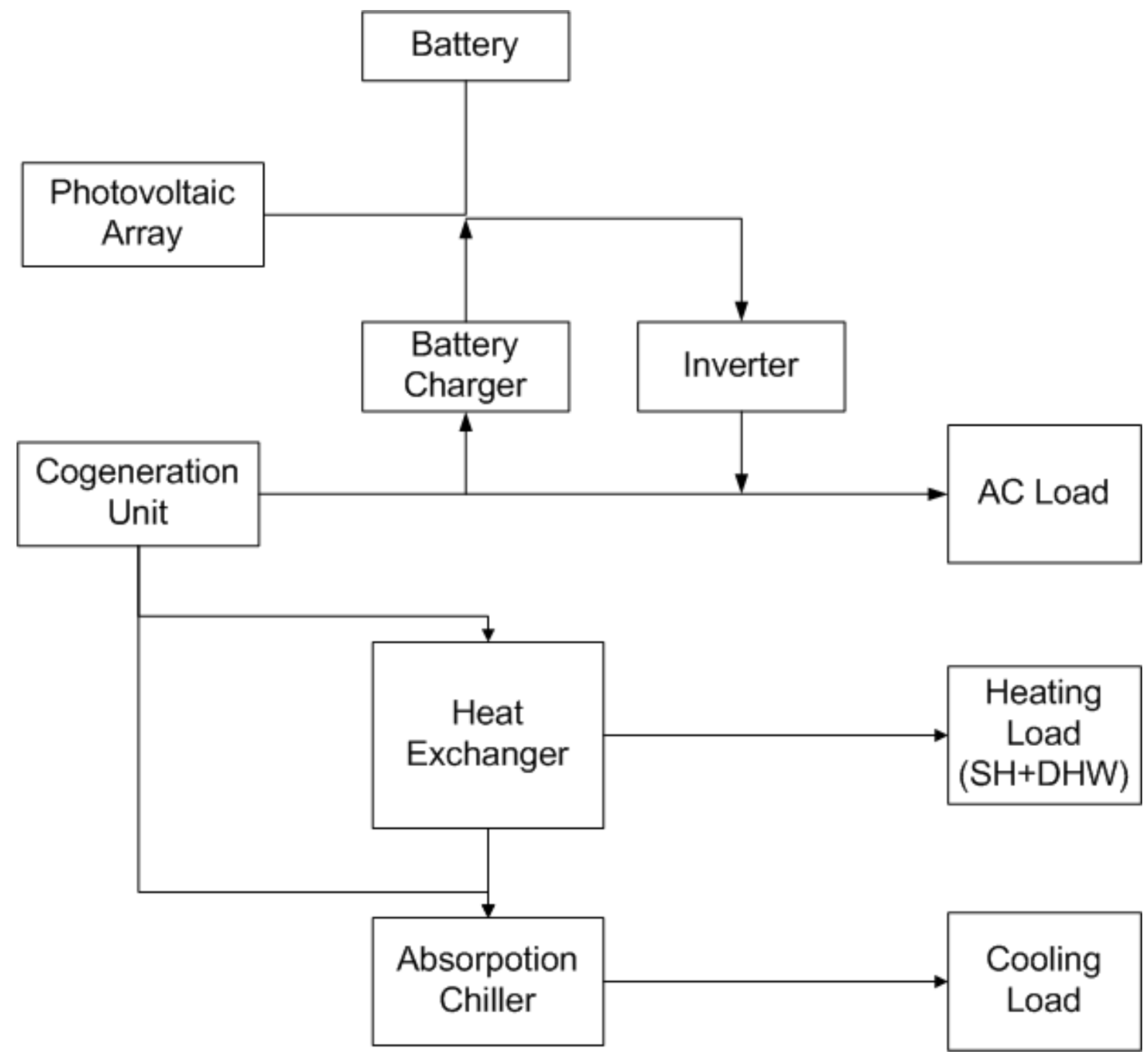

Figure 1- Block Diagram of PV-CCHP system 
Published as: Amir Nosrat and Joshua M. Pearce, "Dispatch Strategy and Model for Hybrid Photovoltaic and Combined Heating, Cooling, and Power Systems”, Applied Energy 88 (2011) 3270-3276. http://dx.doi.org/10.1016/j.apenergy.2011.02.044

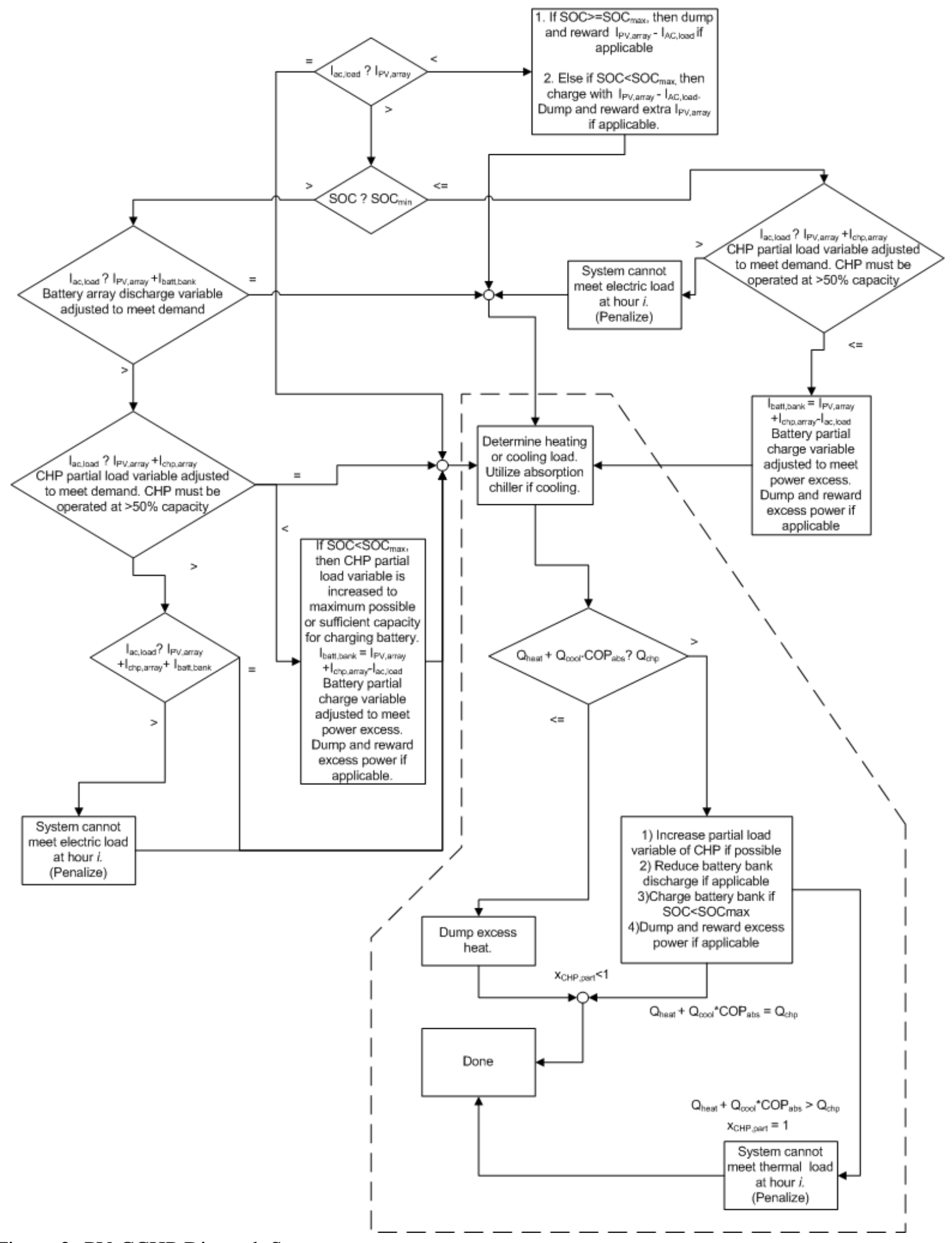

Figure 2- PV-CCHP Dispatch Strategy 
Published as: Amir Nosrat and Joshua M. Pearce, "Dispatch Strategy and Model for Hybrid Photovoltaic and Combined Heating, Cooling, and Power Systems", Applied Energy 88 (2011) 3270-3276. http://dx.doi.org/10.1016/j.apenergy.2011.02.044

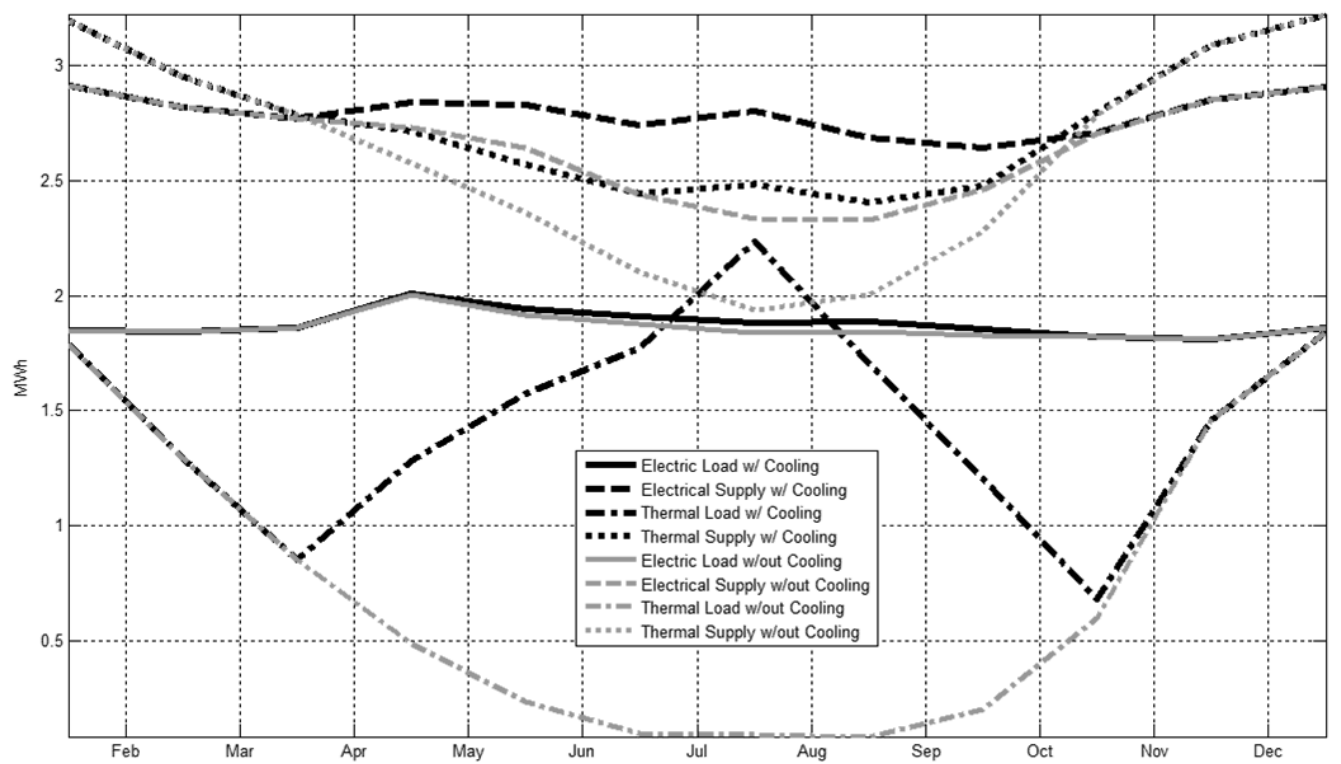

Figure 3- PV-CCHP Monthly Thermal and Electrical Performance With and Without Cooling

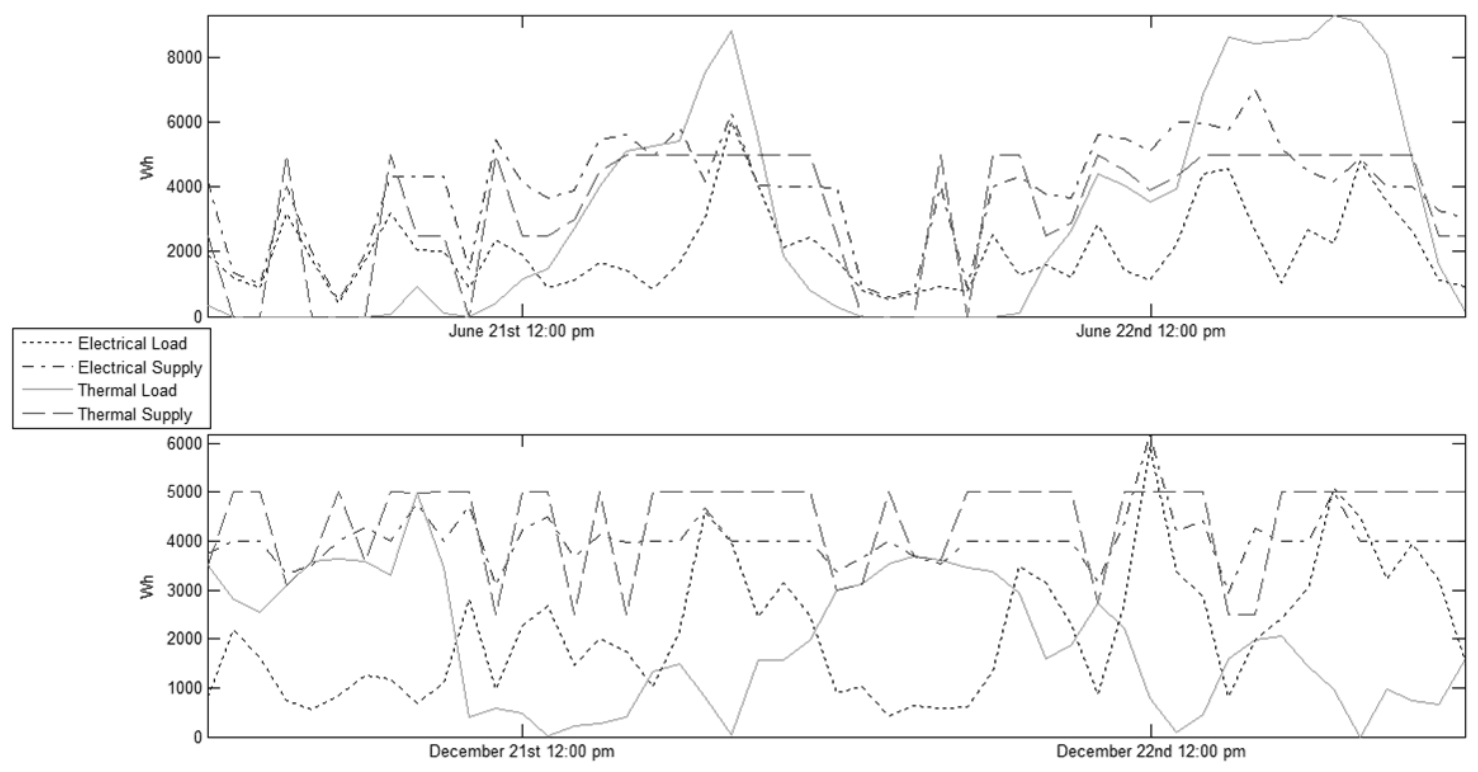

Figure 4- PV-CCHP Hourly Performance with Cooling Load 
Published as: Amir Nosrat and Joshua M. Pearce, "Dispatch Strategy and Model for Hybrid Photovoltaic and Combined Heating, Cooling, and Power Systems", Applied Energy 88 (2011) 3270-3276. http://dx.doi.org/10.1016/j.apenergy.2011.02.044

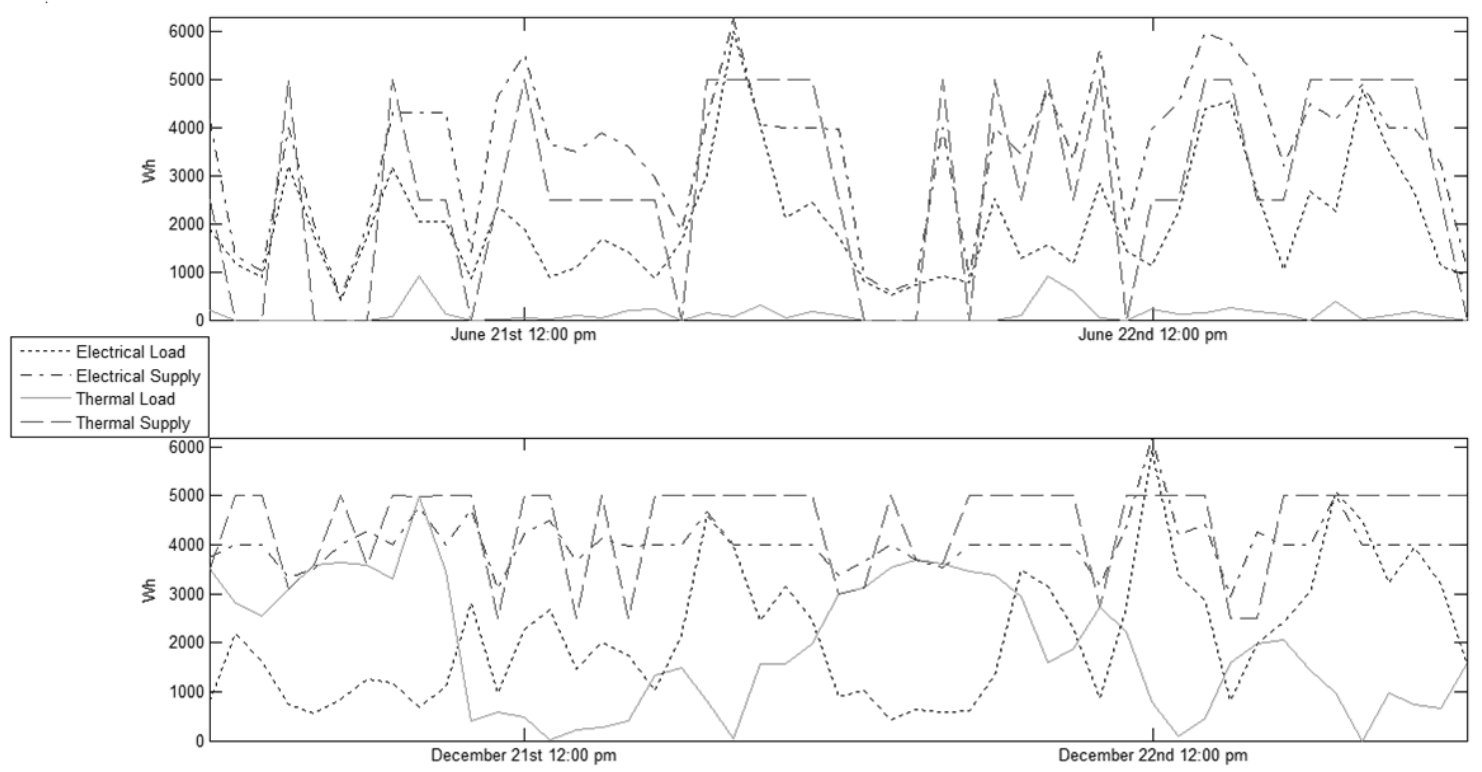

Figure 5-PV-CCHP Hourly Performance without Cooling Load 
Published as: Amir Nosrat and Joshua M. Pearce, "Dispatch Strategy and Model for Hybrid Photovoltaic and Combined Heating, Cooling, and Power Systems”, Applied Energy 88 (2011) 3270-3276. http://dx.doi.org/10.1016/j.apenergy.2011.02.044

\section{Nomenclature:}

\begin{tabular}{|c|c|}
\hline IAC,Ioadi & Demand current of AC load at hour i (A) \\
\hline IPV,arrayi & Supply current of PV array at hour i (A) \\
\hline Ibatt,banki & Charge $(+)$ or discharge $(-)$ current of battery bank at hour i (A) \\
\hline ICHP,arrayi & Supply current of CHP array at hour i (A) \\
\hline Ibatt,bank,possiblei & Maximum possible charge or discharge current of battery bank at hour $i$ (A) \\
\hline VAC,load & Voltage of user load (V) \\
\hline Vbatt,bank & Voltage of battery bank (V) \\
\hline xCHP,part,ji & Partial load variable of CHP output ( 0 or $0.5-1)$ \\
\hline xbatt,parti & Partial load variable of battery output $(0-1)$ \\
\hline xCHP,nom,jkWe & Electrical capacity of CHP unit of type $j(\mathrm{~kW})$ \\
\hline xCHP,nom,jkWth & Thermal capacity of CHP unit of type $j(\mathrm{~kW})$ \\
\hline QCHP,arrayi & Thermal supply of CHP array at hour $i(\mathrm{kWh})$ \\
\hline nchrgentrl & Efficiency of charge controller \\
\hline ninv & Efficiency of inverter \\
\hline $\operatorname{ch}(i)$ & Indicator charge or discharge of batteries. 1 if charging and 0 if discharging \\
\hline$S O C_{j}(i)$ & State of charge of individual battery of type $j$ at hour $i(\mathrm{Ah})$ \\
\hline$S O C_{\max , j}$ & Maximum allowable state of charge of individual battery of type $j(\mathrm{Ah})$ \\
\hline SOCmin & Minimum allowable state of charge of individual battery of type $j(\mathrm{Ah})$ \\
\hline COPabs & Absorption chiller coefficient of performance \\
\hline Qheati & Space heating and domestic hot water load demand $(\mathrm{kWh})$ \\
\hline Qcooli & Space cooling load demand $(\mathrm{kWh})$ \\
\hline
\end{tabular}

